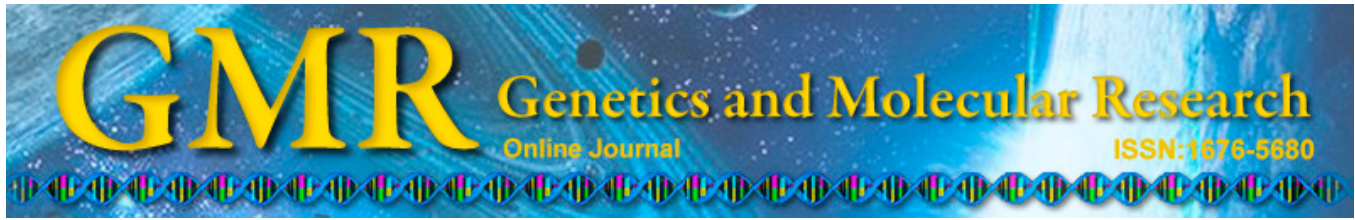

\title{
Construction of recombinant human IFN $\alpha-2 b$ BCG and its antitumor effects on bladder cancer cells in vitro
}

\author{
E. Sun ${ }^{1 *}, X$. Nian $^{1 *}, C \cdot \operatorname{Liu}^{1}, X \cdot \operatorname{Fan}^{3}$ and R. $\operatorname{Han}^{1}$ \\ ${ }^{1}$ Department of Urology, The Second Hospital of Tianjin Medical University, \\ Tianjin Institute of Urology, Tianjin, China \\ ${ }^{2}$ The First Central Hospital of Tianjin, Tianjin, China \\ ${ }^{3}$ Tianjin Central Hospital of Gynecology Obstetrics, Tianjin, China \\ *These authors contributed equally to this study. \\ Corresponding author: R. Han \\ E-mail: hanruifa2013@sina.com
}

Genet. Mol. Res. 14 (2): 3436-3449 (2015)

Received November 4, 2013

Accepted October 17, 2014

Published April 15, 2015

DOI http://dx.doi.org/10.4238/2015.April.15.7

ABSTRACT. We constructed recombinant Bacille Calmette-Guérin
(rBCG) that secreted human interferon alpha $2 \mathrm{~b}$ (hIFN $\alpha-2 \mathrm{~b}$ ), and
investigated its antitumor effects on bladder cancer cells in vitro. The
recombinant plasmid phIFN- $\alpha-2 \mathrm{~b}$ was constructed using pMAO-4 and
transformed into BCG. The supernatant was collected at various times
and IFN- $\gamma$, interleukin (IL)-12, and tumor necrosis factor (TNF)- $\alpha$ were
detected using an enzyme-linked immunosorbent assay. EJ cells were
cultivated for 24,48 , and $72 \mathrm{~h}$, together with rBCG, wild-type BCG
(wBCG), or wBCG+IFN- $\alpha-2 b$. rBCG capable of secreting cytokine
IFN $\alpha-2 b$ was constructed. On the 4 th day of culture, the IFN $\alpha-2 b$
secreted by rBCG reached a maximum. wBCG and rBCG showed no
significant difference on cell growth rate over 7 days of incubation
in $7 \mathrm{H} 9$ medium. wBCG and rBCG were both positive for acid-fast
staining, and showed mycobacterial characteristics of intercellular
connection in clusters with no clear abnormalities. Higher levels 
of IFN- $\gamma$, TNF- $\alpha$, and IL-12 were induced by $\mathrm{rBCG}$ compared with wBCG or MAO4-rBCG $(\mathrm{P}<0.05)$. rBCG may induce lymphocyte proliferation; the proliferation ratio was higher than those induced by wBCG and wBCG+IFN. rBCG had direct anti-proliferative effects on EJ cells. An MTT assay showed that $\mathrm{rBCG}$ inhibited the proliferation of bladder cancer cells and had more activity compared with wBCG $(\mathrm{P}<$ $0.05)$. The highest anti-tumor activity of lymphocytes was stimulated by rBCG (20.31-51.22\%). rBCG-IFN $\alpha$-2b induces enhanced cytotoxicity against bladder cancer cells in vitro and may be used as an alternative to $\mathrm{BCG}$ for bladder cancer patients.

Key words: Bacilli Calmette-Guérin; Bladder tumor; EJ cells; rBCG; IFN $\alpha-2 b$; Peripheral blood monocytes

\section{INTRODUCTION}

Immunotherapy with intravesical administration of Bacillus Calmette-Guérin (BCG) is an effective alternative approach to chemotherapy for managing superficial transitional cell carcinoma of the bladder (Alexandroff et al., 1999; Luo et al., 2001). In 1976, Morales et al. first reported the intravesical use of BCG for treating superficial carcinoma of the bladder. BCG has been shown to eradicate residual tumors in $\geq 60 \%$ of patients with papillary disease and $\geq 70 \%$ of patients with carcinoma in situ. However, there are numerous limitations to the use of intravesical administration of BCG. For instance, treatment failure including recurrence and progression has been reported depending on the tumor stage and/or histology grade.

The antitumor effects of BCG occur primarily through regulation of the host immune system. In experimental studies, the cytokines interleukin (IL)-2, tumor necrosis factor (TNF), and interferon (IFN)- $\gamma$ were released in the presence of BCG stimulation, which played a crucial role in the T-cell and natural killer cells effects on bladder cancer. However, there are some adverse events related to BCG immunotherapy. Local adverse reactions with an incidence of $27-95 \%$ were observed in patients who underwent immunotherapy. Moreover, severe systemic side events can occur, which caused great threats to the safety of the patients.

In cultured murine MB49 bladder tumor cells, combination of BCG and IFN- $\alpha$ had superior and earlier antitumor activity than $\mathrm{BCG}$ alone. It has been reported that recombinant BCG (rBCG)-S1PT immunotherapy resulted in bladder weight reduction compared with a single BCG treatment group and control group. Recently, the use of rBCG technology has increased for developing immunotherapeutic agents with specific targets (Sarosdy and Kierum, 1989; Gan et al., 1999). Genetic engineering technology can be used to transform wild-type BCG into $\mathrm{rBCG}$ that can secrete cytokines. $\mathrm{rBCG}$ can reduce not only the BCG dosage but also side effects through the continuous secretion of cytokines to overcome the disadvantages associated with the direct use of cytokines including perfusion because of its short half-life, water-solubility, ease of urine loss, need for a large number of perfusions, and higher cost. Other than BCG, IFN $\alpha-2 b$ has been used with some success as an intravesical agent for superficial bladder cancer. However, its response rate of $40 \%$ has been overshadowed by that of BCG (Luo et al., 1996; Gan et al., 1999). Nevertheless, a significant number of BCG nonresponders have been cured with IFN $\alpha-2 b$ (Lamm, 1992). In contrast to BCG, intravesical IFN $\alpha$ therapy has few and typically mild side effects (Luo et al., 1996; Gan et al., 1999). 
In this study, hIFN $\alpha-2 b$-expressing $\mathrm{rBCG}$ was constructed to confirm whether $\mathrm{rBCG}$ promotes the secretion of Th1-type immune factors in peripheral blood mononuclear cells (PBMCs). In addition, we investigated the direct inhibition effect of hIFN $\alpha-2 b-r B C G$ on a bladder cancer cell line and the lethal effects of the activated peripheral blood lymphocytes on EJ bladder tumor cells.

\section{MATERIAL AND METHODS}

\section{Plasmids and bacterial strains}

Escherichia coli DH5 $\alpha$ cells were provided by Tianjin Institute of Urology (Tianjin, China). Danish BCG D2BP302 was purchased from the Beijing Institute of Biological Products (Beijing, China). Plasmid pMAO-4 and the plasmid containing hIFN $\alpha-2 b$ cDNA were kindly provided by Prof. Y. Luo from the University of Iowa (Iowa City, IA, USA).

\section{Main reagents}

Middlebrook 7H9 Broth (Difco), Middlebrook 7H10 Agar (Difco), T4DNA Ligase, BamHI, EcoRI, NcoI, BspHI, ClaI, NlaIII, Taq enzyme, the E.Z.N.A Gel Extraction Kit, DNA Fragment Purification Kit Ver 2.0, and the Wizard Purification Plasmid DNA Purification System were purchased from TaKaRa Co., Ltd. (Dalian, China). Human IFN- $\alpha$, IFN- $\gamma$, TNF- $\alpha$, IL-12, and the enzyme-linked immunosorbent assay (ELISA) kits were purchased from eBioscience, Inc. (San Diego, CA, USA). IFN $\alpha$-2b and 3-(4,5-dimethylthiazol-2-yl)-2,5-diphenyltetrazolium bromide (MTT) were purchased from Sigma (St. Louis, MO, USA).

\section{Human bladder cancer cell line and effector cell preparation}

Human bladder cancer EJ cells were obtained from American Type Culture Collection (Rockville, MD, USA). The cells were cultured in RPMI 1640 medium (Gibco, Grand Island, NY, USA) supplemented with $10 \%$ fetal bovine serum (FBS), $100 \mathrm{U} / \mathrm{mL}$ penicillin-G, and 100 $\mathrm{g} / \mathrm{mL}$ streptomycin in a humidified air $/ 5 \% \mathrm{CO}_{2}$ incubator at $37^{\circ} \mathrm{C}$.

PBMCs were isolated from heparinized blood samples using standard Ficoll-Paque centrifugation. The cellular viability of PBMCs was determined using a trypan blue exclusion assay. Cells were cultured in RPMI 1640 medium supplemented with $10 \% \mathrm{FBS}, 50 \mu \mathrm{M}$ $\beta$-mercaptoethanol, and $30 \mathrm{~g} / \mathrm{mL}$ kanamycin at $37^{\circ} \mathrm{C}$ in $5 \% \mathrm{CO}_{2}$. To define the type of effector cells involved in the enhancement of rBCG-mediated PBMC cytotoxicity on bladder cancer cells, CD8+ T lymphocytes were isolated from PBMCs after BCG stimulation using the MACS negative selection kits (130-094-156 for CD8+ T lymphocyte cells), and then used as effector cells in the antitumor assay.

\section{Construction of pMAO-4-hIFN $\alpha-2 b$}

cDNA was synthesized using M-MLV reverse transcriptase (Invitrogen, Carlsbad, CA, USA) according to manufacturer instructions. Amplification of hIFN $\alpha-2 b$ cDNA was carried out using a Geneamp PCR 2400 system (PerkinElmer Inc., Waltham, MA, USA). The primers used for hIFN $\alpha-2 \mathrm{~b}$ were 5'-CAAGggatccTGTGATCTGCCTCAAACCCA-3'and 
5'-GCCGgaattcTCATTCCTTACTTAAACTTT-3'. The cDNA of Nrf2 was amplified by polymerase chain reaction (PCR) (predenaturation at $94^{\circ} \mathrm{C}$ for $5 \mathrm{~min} ; 30$ cycles: $94^{\circ} \mathrm{C}, 30 \mathrm{~s} ; 55^{\circ} \mathrm{C}$, $50 \mathrm{~s}$; and $72^{\circ} \mathrm{C}, 50 \mathrm{~s}$; and a final extension at $72^{\circ} \mathrm{C}$ for $7 \mathrm{~min}$ ) using $150 \mu \mathrm{g} / \mathrm{mL} \mathrm{cDNA}$ template according to manufacturer instructions. Subsequently, the mixture was digested with BamHI and $E c o$ RI in a $40-\mu \mathrm{L}$ total reaction volume containing $50 \mu \mathrm{g} / \mathrm{mL}$ pMAO- 4 and $30 \mu \mathrm{g} / \mathrm{mL}$ hIFN $\alpha-2 b$ cDNA at $37^{\circ} \mathrm{C}$ for $10 \mathrm{~h}$.

DNA purification was performed according to manufacturer instructions. Subsequently, hIFN $\alpha-2 b$ cDNA was linked to the pMAO-4 plasmid by T4 DNA Ligase. Next, $100 \mu \mathrm{L}$ DH5 $\alpha$ competent bacteria was mixed with $1 \mu \mathrm{L}$ recombinant plasmid and placed in an ice bath for $30 \mathrm{~min}$, heat-shocked at $42^{\circ} \mathrm{C}$ for $45 \mathrm{~s}$, and placed in an ice bath for $5 \mathrm{~min}$. After adding $0.9 \mathrm{~mL}$ Luria-Bertani (LB) medium, the mixture was cultured at $37^{\circ} \mathrm{C}$ for $90 \mathrm{~min}$. Finally, the mixture was inoculated onto LB solid medium containing $30 \mu \mathrm{g} / \mathrm{mL}$ kanamycin, and incubated at $37^{\circ} \mathrm{C}$ for $24 \mathrm{~h}$. To validate the DNA sequence of pMAO-4-hIFN $\alpha-2 \mathrm{~b}$, gene sequencing was carried out.

\section{Construction of rBCG-hIFN $\alpha-2 b$}

BCG was cultured in Middlebrook $7 \mathrm{H} 9$ medium in a shaker at $37^{\circ} \mathrm{C}$ until an optical density at $600 \mathrm{~nm}\left(\mathrm{OD}_{600}\right)$ of 0.5 was reached. A total of $100 \mu \mathrm{L}$ competent $\mathrm{BCG}$ and 10 $\mu \mathrm{g}$ pMAO4-IFN $\alpha-2 \mathrm{~b}$ were mixed to construct recombinant BCG according to the previous description (Figure 1). After $1.5 \mathrm{~h}$ of incubation in an ice bath, the sample was centrifuged at $2800 \mathrm{~g}$ for $10 \mathrm{~min}$. Next, $20 \mathrm{~mL} 4^{\circ} \mathrm{C}$-precooled $10 \%$ glycerol was used to wash the precipitate, the sample was centrifuged, and the wash was repeated. The pellet was resuspended in $10 \%$ precooled glycerol and the resulting mixture containing BCG was divided into several $1.5-\mathrm{mL}$ tubes for immediate electroporation or storage at $-70^{\circ} \mathrm{C}$ for later use. Approximately $5-15 \mu \mathrm{g}$ prepared plasmid DNA (dissolved in 10-20 $\mu \mathrm{L}$ ) was added to $100 \mu \mathrm{L}$ competent BCG. The total volume of $\leq 150 \mu \mathrm{L}$ was mixed for electro-transduction at a voltage of $1.8 \mathrm{kV}$. Next, 1 $\mathrm{mL} 7 \mathrm{H} 9$ medium was added and the sample placed in a shaking incubator for $5 \mathrm{~h}$ at $35^{\circ} \mathrm{C}$. The culture was coated onto $7 \mathrm{H} 10$ solid medium with $30 \mu \mathrm{g} / \mathrm{mL}$ kanamycin for incubation at $37^{\circ} \mathrm{C}$. After 4-6 weeks, colony selection was carried out. Positive colonies were picked after 3-4 weeks and verified by acid-fast staining. Acid-fast staining is used to observe morphological changes. rBCG-IFN $\alpha-2 b$ plasmids were extracted and human IFN $\alpha-2 b$ was amplified using the same primer pairs. The size of the insert was confirmed by electrophoresis. rBCG-IFNa$2 \mathrm{~b}$ was induced by temperature-shift induction and hydrogen peroxide. After electrophoresis, PCR products were purified and prepared for sequencing.

\section{Identification of positive colonies and growth characteristics}

A single colony grown on the selection plate was picked for inoculation into $10 \mathrm{~mL}$ $7 \mathrm{H} 9$ liquid medium containing $30 \mu \mathrm{g} / \mathrm{mL}$ kanamycin at $37^{\circ} \mathrm{C}$ at $150 \mathrm{rpm}$ with shaking. After reaching an $\mathrm{OD}_{600}$ of $1,1 \mathrm{~mL}$ sample was centrifuged at $10,000 \mathrm{rpm}$ for $10 \mathrm{~min}$. The pellet was washed 3 times with deionized distilled $\mathrm{H}_{2} \mathrm{O}\left(\mathrm{ddH}_{2} \mathrm{O}\right)$ and then $30 \mu \mathrm{L} \mathrm{ddH_{2 }} \mathrm{O}$ was added to dissolve the sediment. The sample was boiled for $10 \mathrm{~min}$, centrifuged at $10,000 \mathrm{rpm}$ for $10 \mathrm{~min}$, and $20 \mu \mathrm{L}$ supernatant was used as a template for PCR analysis. The protocol was the same as that used for hIFN $\alpha-2 b-c D N A$. After electrophoresis, the PCR products were removed from the gel to purify the sequencing templates. The primer 5'-CAAGGGATCCTGTGATCTGCC 
TCAAACCC-3' was used for sequencing.

hIFNa-2b-rBCG, MAO4-rBCG, and BCG cultures were separately inoculated into 50 $\mathrm{mL} 7 \mathrm{H} 9$ medium, each in 3 bottles, and OD was measured. Microscopic morphology was observed after acid-fast staining. To $1 \mathrm{~mL}$ bacterial culture solution, $9 \mathrm{~mL} 7 \mathrm{H} 9$ medium was added, and this dilution procedure was repeated an additional 4 times (i.e., 1:10,000 and 1:100,000). Next, the diluted solution was used for inoculation onto $7 \mathrm{H} 10$ solid medium containing $30 \mu \mathrm{g} /$ $\mathrm{mL}$ kanamycin, and then cultured at $37^{\circ} \mathrm{C}$ for 4 weeks. The average after counting the results of 3 dishes of the same concentration was used to calculate the number of viable cells per $\mathrm{mL}$ BCG. Viable BCG count $=\left(\right.$ colony number of 1:10,000 $\times 10^{5}+$ colony number of $1: 100,000 \mathrm{x}$ $10^{6}$ ) / 2 . When $\mathrm{A}_{600}=1, \mathrm{rBCG}$ was approximately $1.4 \times 10^{8}$ colony-forming units (CFU).

\section{hIFN $\alpha-2 b$ expression detection}

The bacterial culture of hIFN $\alpha-2 b-r B C G$ or MAO4-rBCG was centrifuged at 10,000 rpm for $10 \mathrm{~min}$. Expression of secreted extracellular hIFN $\alpha-2 \mathrm{~b}$ was detected. The pellet was washed 3 times, $100 \mu \mathrm{LddH}_{2} \mathrm{O}$ was added, and the sample was ultrasonicated in an ice bath until the solution was clear. Next, the sample was centrifuged at $10,000 \mathrm{rpm}$ for $10 \mathrm{~min}$ to collect the supernatant containing hIFN $\alpha-2 b$. The level of hIFN $\alpha-2 b$ was determined using an ELISA according to manufacturer instructions. Each sample was taken in triplicate and each specimen was tested in 2 wells. Sample content was determined according to the standard curve.

\section{Changes in hIFN $\alpha$-2b secretory dynamics in vitro}

rBCG single colonies were cultured in 7H9 medium in 200-mL Erlenmeyer flasks, and were placed in a shaking incubator at $38^{\circ} \mathrm{C}$ and $150 \mathrm{rpm}$ under constant humidity. Next, $1 \mathrm{~mL}$ sample was acquired every day for 10 days. The $\mathrm{OD}_{600}$ was measured using a spectrophotometer. Bacteria in the medium were centrifuged at $4000 \mathrm{rpm}$ to collect the supernatant. The supernatant was stored at $20^{\circ} \mathrm{C}$ and used to detect changes in hIFN $\alpha-2 b$ secreted from $\mathrm{rBCG}$ at different growth cycles. IFN $\alpha-2 \mathrm{~b}$ protein level was determined by ELISA according to manufacturer instructions.

\section{Th1-type cytokines secreted by PBMCs}

PBMC extracts were freshly prepared from the peripheral blood of healthy subjects. hIFNa-2b-rBCG, MAO4-rBCG, and BCG were co-cultured with PBMCs on 24-well plates. The final concentration of bacteria was $1.4 \times 10^{6} \mathrm{CFU} / \mathrm{mL}$ and that of the cells was $1.0 \times 10^{5}$ cells $/ \mathrm{mL}$. A sample containing only PBMCs was used as a blank control. After culturing in a $\mathrm{CO}_{2}$ incubator, the supernatant was collected at $12,24,48$, and $72 \mathrm{~h}$, as well as at 5 and 7 days and stored at $70^{\circ} \mathrm{C}$. The cytokines IFN- $\gamma$, TNF- $\alpha$, and IL- 12 were detected by ELISA according to the manufacturer protocol.

\section{Lymphocyte proliferative activity detection}

Lymphocytes were isolated from PBMCs as effector cells and divided into a control group and 3 experimental groups (rBCG group, wild-type BCG group, and wild-type BCG plus IFN- $\alpha$ group). Lymphocytes were cultured for $2 \mathrm{~h}$. Lymphocytes unattached to a $24-w e l l$ 
cell culture plate were collected and the concentration adjusted to $2 \times 10^{5} / \mathrm{mL}$. The final concentration of BCG was $1.4 \times 10^{6} \mathrm{CFU} / \mathrm{mL}$, with $1 \mathrm{~mL}$ in each well. After co-culture for 0,24 , 48 , and $72 \mathrm{~h}, 100 \mu \mathrm{L}$ was added to a 96-well plate.

\section{Measurement of bladder tumor growth inhibited directly by rBCG}

Bladder tumor EJ cells $\left(1 \times 10^{5} / \mathrm{mL}\right.$ density $)$ were cultured during the logarithmic phase and inoculated on a 96-well plate, cultured for $16 \mathrm{~h}$ to allow complete attachment to the plate, and rBCG, wild-type BCG, and wild-type BCG plus IFN- $\alpha$ in mixed composition were added to the plate. The 3 groups were cultured at $37^{\circ} \mathrm{C}$ in saturated humidity and $5 \% \mathrm{CO}_{2}$ for 24 and $72 \mathrm{~h}$. Next, $20 \mu \mathrm{L} 5 \mathrm{mg} / \mathrm{mL}$ MTT was added to the wells and the plate was cultured for $4 \mathrm{~h}$. The plate was centrifuged and the supernatant was discarded. Next, dimethyl sulfoxide was added to dissolve the pellet. An enzyme-linked immune detector was used to measure the concentration at $570 \mathrm{~nm}$. Six wells were measured to calculate the mean. The following equation was used to determine the cell growth inhibition rate: cell growth inhibition rate $(\%)=$ (control group A value - treatment group A value) / control group A value x $100 \%$.

\section{Measurement of the killing effect of BCG-activated lymphocytes on tumor cells by a lactate dehydrogenase $(\mathrm{LDH})$ release test}

Lymphocytes were cultured for $2 \mathrm{~h}$, after which the concentration was adjusted to $4 \times 10^{5} / \mathrm{mL}$; rBCG, wild-type BCG, and wild-type BCG plus IFN- $\alpha$ were added and then cocultured at $37^{\circ} \mathrm{C}$ in $5 \% \mathrm{CO}_{2}$ in a saturated humid atmosphere for $72 \mathrm{~h}$. In the LDH release experiment, the effector cells were lymphocytes that had been divided into experimental and control groups, while the target cells were EJ bladder cancer cells. The effector to target ratio was $50: 1$. Next, $0.1 \mathrm{~mL}$ of each proliferating lymphocytes and EJ cells were mixed and incubated at $37^{\circ} \mathrm{C}$ in $5 \% \mathrm{CO}_{2}$ for $4 \mathrm{~h}$; incubation was carried out at $37^{\circ} \mathrm{C}$ for $10 \mathrm{~min}$, after which additional substrate liquid was added and an ultraviolet spectrometer at $340 \mathrm{~nm}$ was used for measurements at $30 \mathrm{~s}, 1 \mathrm{~min}, 2 \mathrm{~min}$, and $3 \mathrm{~min}$ to determine the A value. The following formula was used to determine kill activity: kill activity $(\%)=(\mathrm{LDH}-\mathrm{L}-$ natural release LDH-L $)$ / (maximum release LDH-L - natural release LDH-L) x 100\%.

\section{Statistical analysis}

All data are reported as means \pm standard deviation. SPSS18.0 was used for statistical analysis (SPSS, Inc.; Chicago, IL, USA). The chi-square test was used for intra-group comparisons, whereas the Student $t$-test was performed for inter-group comparisons. $\mathrm{P}<0.05$ was considered to indicate a significant difference.

\section{RESULTS}

\section{Construction and characterization of pMAO4-hIFN $\alpha-2 b$}

The upstream primer contained BamHI restriction sites, while the downstream primer contained $E c o$ RI restriction sites. The plasmid containing hIFNa-2b cDNA was used as a template for the PCR. A 500-bp hIFN $\alpha-2$ b cDNA fragment was obtained after BamHI and EcoRI 
digestion as indicated in Figure 1. Double-digestion using BamHI and EcoRI was carried out for the PCR products, and a 500-bp fragment was identified after electrophoresis (Figure 2, left). A DNA fragment (approximately $5 \mathrm{~kb}$ ) was obtained after Bam $\mathrm{HI}$ and EcoRI digestion of pMAO4 (Figure 2, right). The recombinant plasmid phIFN- $\alpha-2 b$ formed using the digested fragments was transformed into E. coli, which showed many scattered, smooth, yellow-white colonies after culture. After double-digestion and electrophoresis, a 500-bp band (hIFN- $\alpha-2 \mathrm{~b}$ cDNA) and a 5-kb band (pMAO-4 digested fragments) were identified (Figure 2, left). After PCR with both primers designed based on the sequences of the cloning site ends, a band of approximately 500 bp appeared on the gel after electrophoresis (Figure 2, right). Sequencing demonstrated that the hIFN $\alpha-2 b$ sequence cloned into pMAO4-hIFN $\alpha-2 b$ was identical to that in GenBank.
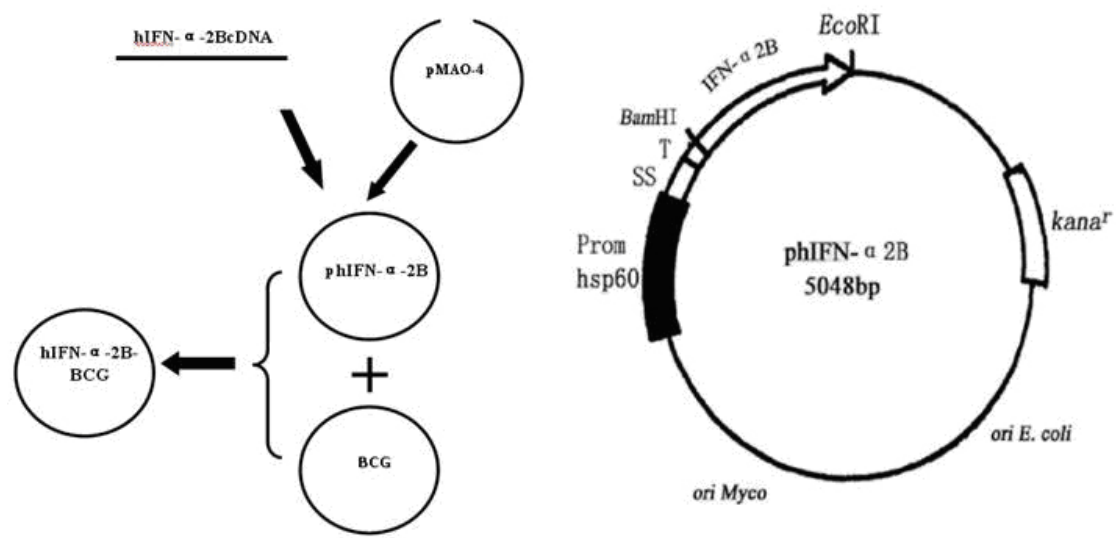

Figure 1. Construction strategy of recombinant BCG and plasmid profile of phIFN- $\alpha-2 B$.

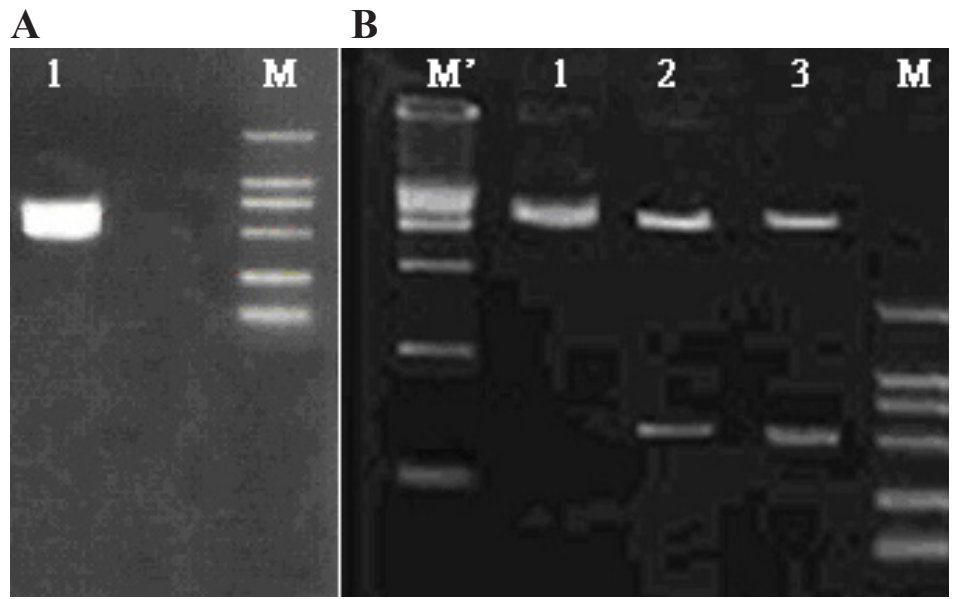

Figure 2. A. Electrophoresis results of digested PCR product of hIFN- $\alpha-2 \mathrm{~B}-\mathrm{cDNA}$. Lane 1, PCR products of hIFN$\alpha-2 \mathrm{~B}-\mathrm{cDNA}$ were treated by $B a m \mathrm{HI}, E c o$ RI double digestion reaction, to produce $500 \mathrm{bp}$ fragment with sticky ends; lane $M=$ DNA marker DL2000 (bands from bottom: 100, 250, 500, 750, $1 \mathrm{k}, 2 \mathrm{kbp}$ ). B. Electrophoresis results of phIFN- $\alpha-2 \mathrm{~B}$ before and after digestion: lane $M=$ DNA marker DL15000 (from bottom $250,1 \mathrm{k}, 2.5 \mathrm{k}$, $5 \mathrm{k}, 7.5 \mathrm{k}, 10 \mathrm{k}, 15 \mathrm{kbp}$ ); lane $1=$ pMAO-4 by BamHI and EcoRI double digestion; lanes 2-3 = double-digested plasmids phIFN- $\alpha-2 \mathrm{~B}$, yield two bands about $500 \mathrm{bp}$ (hIFN- $\alpha-2 \mathrm{~B}$ cDNA) and $5 \mathrm{~kb}$ (cutting-off pMAO-4); lane $M$ $=$ DNA marker DL2000. 
A

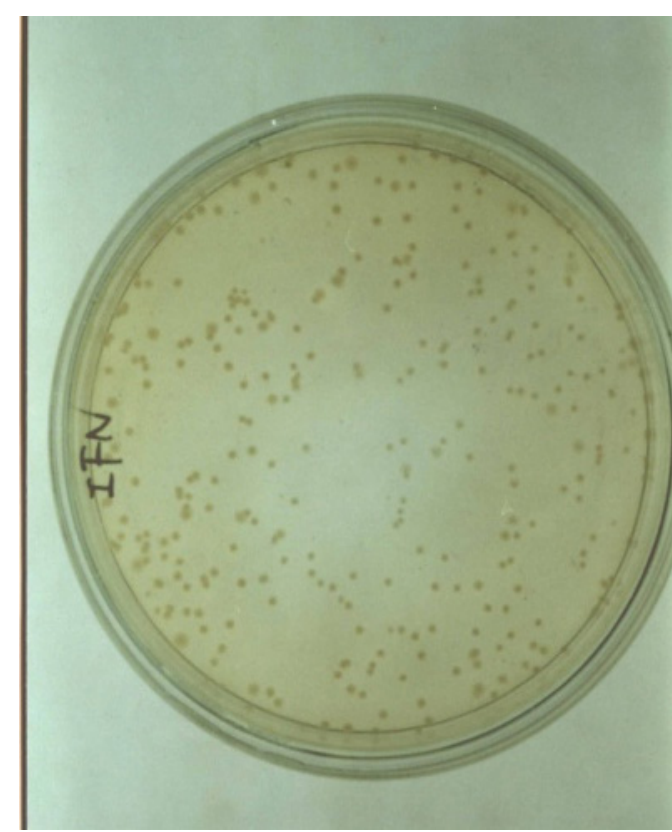

B

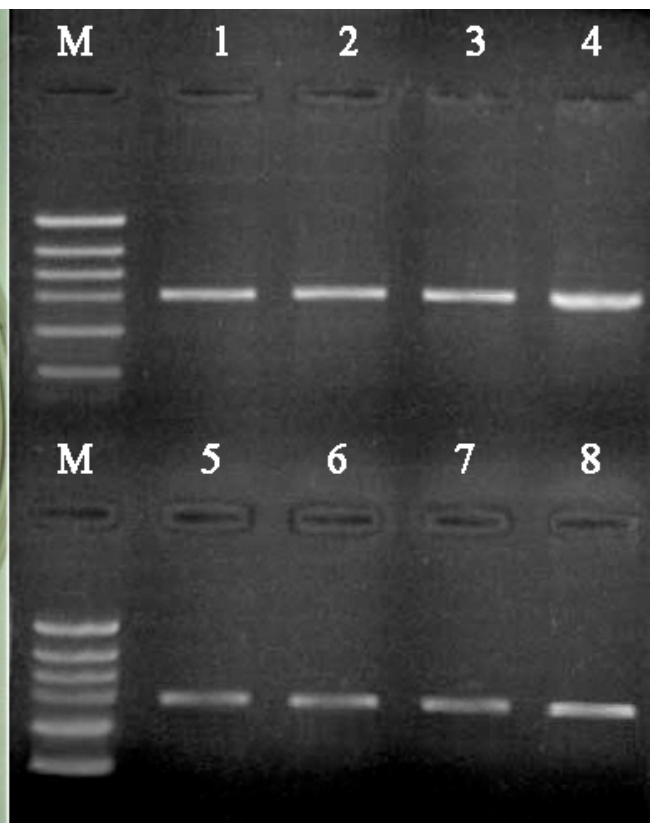

Figure A. Formation of single colony after phIFN- $\alpha-2 b$ transformed into Escherichia coli. The smooth yellowwhite colony appeard on LB solid medium in the presence of kanamycin, after culture for $10 \mathrm{~h}$. B. Electrophoresis results of phIFN- $\alpha-2 \mathrm{~B}$ PCR products. Lane $M=$ DNA marker DL2000; lanes $1-7=\mathrm{hIFN}-\alpha-2 \mathrm{~B}$ PCR product of recombinant plasmid phIFN- $\alpha-2 \mathrm{~B}$ multiplicated in electrotransducted $E$. coli growed on the above LB plate, a band of about $500 \mathrm{bp}$; lane $8=$ the PCR result of plasmid containing hIFN- $\alpha-2 \mathrm{~B}$, as positive control.

\section{Construction of rBCG- hIFN $\alpha-2 b$}

Four weeks after electrotransformation, several white, scattered, dry bacterial colonies were identified on the culture dish containing kanamycin. After 6 weeks, colony diameters were $1 \mathrm{~mm}$ as indicated in Figure 3. A PCR with a pair of primers specific to the hIFN $\alpha-2 b$ sequence showed a 500-bp band (Figure 3, right). DNA sequencing results showed that the sequence was identical to that of hIFN $\alpha-2 b$ cDNA in GenBank.

\section{Identification of hIFN $\alpha-2 b-r B C G$ and its growth characteristics}

No significant difference was noted in the growth curves of BCG, MAO4-rBCG, and $\mathrm{rBCG}$ from days 1-7. On day 8, BCG and MAO4-rBCG decreased slightly to $1.22 \pm$ 0.10 and $1.21 \pm 0.09$; rBCG reached a plateau of $1.22 \pm 0.08$ (Figure 4).

No obvious difference was noted between groups (all $\mathrm{P}>0.05$ ). In this study, BCG and $\mathrm{rBCG}$ showed $\mathrm{OD}_{600}$ values of 1 and were $1.4 \times 10^{8} \mathrm{CFU} / \mathrm{mL}$. Similar colony patterns, acid-fast staining characteristics, morphology, and interconnected cluster features were observed, although the microscopic rBCG body was slightly larger than that of BCG (Figure 5). 
A

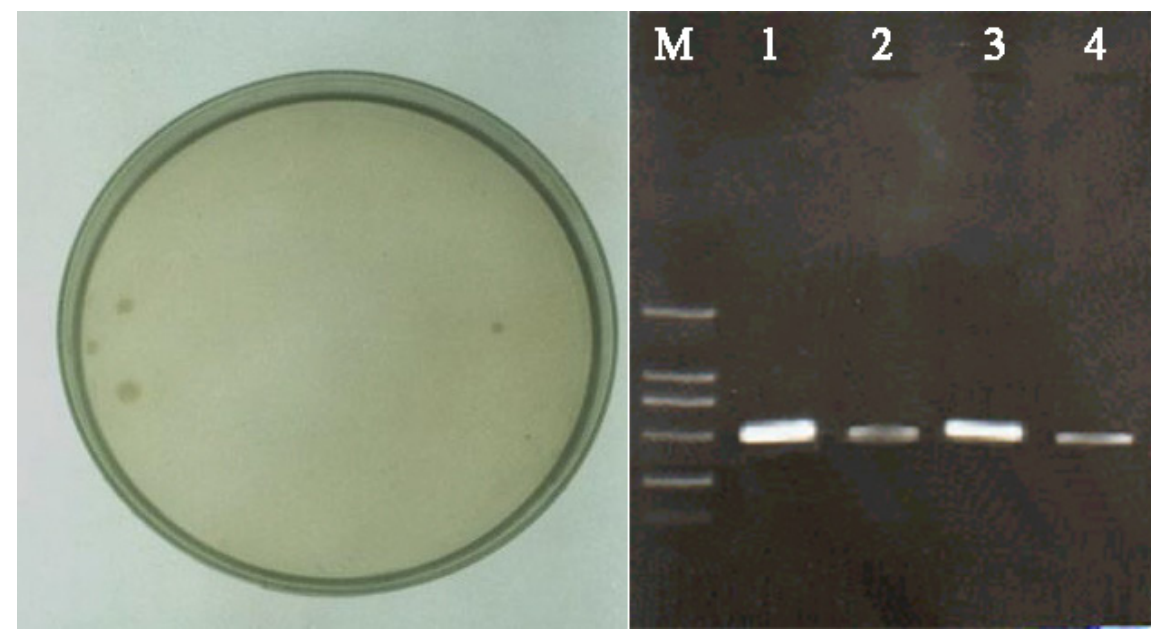

Figure 4. A. Formation of single colony of recombinant BCG transformed by phIFN- $\alpha-2 \mathrm{~B}$. After electrotransformation, culturing for 4 weeks on $7 \mathrm{H} 10$ plate in presence of kanamycin, several yellow-white, scattered, dry surface of recombinant BCG colonies appeared. B. Electrophoresis results of rBCG PCR product: lane $M=$ DNA marker DL2000; lane 1-4 = PCR product of hIFN- $\alpha-2 \mathrm{~B}-\mathrm{rBCG}$ collected from the 7H10 plate, a band of about $500 \mathrm{bp}$.

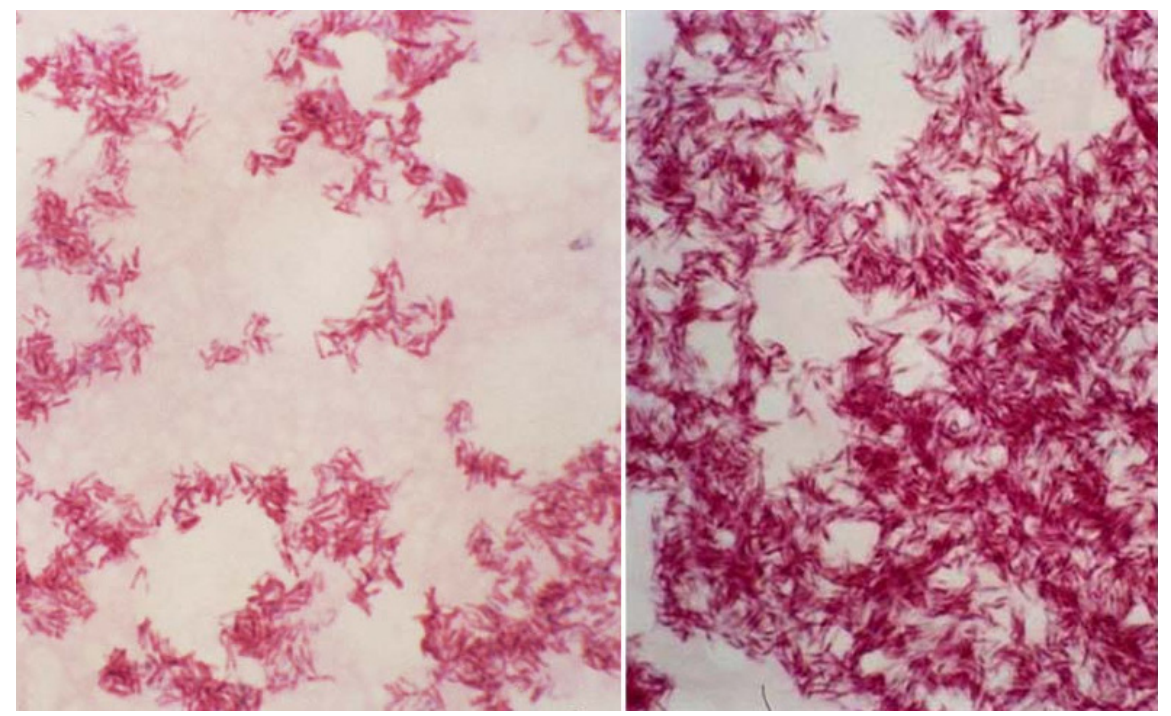

Figure 5. Morphology of anti-acid stained $\mathrm{rBCG}$ and wBCG: wild-type BCG (left), hIFN- $\alpha-2 \mathrm{~b}$ rBCG (right). Similar acid-fast staining characteristics, morphology, and interconnected cluster features, while microscopy $\mathrm{rBCG}$ slightly larger than the wild one. (LMC 1000X).

\section{hIFNa-2b expression}

When rBCG was incubated to approximately $1.4 \times 10^{8} \mathrm{CFU} / \mathrm{mL}$, the content of hIFN$\alpha$-2b secreted by hIFN- $\alpha$-2b-rBCG into the supernatant was $998.0 \pm 9.3 \mathrm{pg} / \mathrm{mL}$, while the intracellular content was $99.2 \pm 3.1 \mathrm{pg} / \mathrm{mL}$. Expression of $\mathrm{hIFN}-\alpha-2 \mathrm{~b}$ by both wild-type BCG 
and MAO4-rBCG was negative. Approximately $100 \mathrm{pg}$ IFN secreted by $\mathrm{rBCG}$ was equal to 1 IU in the activity titer. The dynamics of IFN $\alpha-2 b$ in the supernatant with the growth of $\mathrm{rBCG}$ are shown in Figure 6. From days 4-7 of culture, rapid growth of rBCG was observed, followed by a slow growth period. The initial increase in interferon production was noted on the 3 rd day, reaching a plateau (initial $0_{600}=0.2$ ) from days 6-10.

rBCG growth and expression of interferon curve within a week

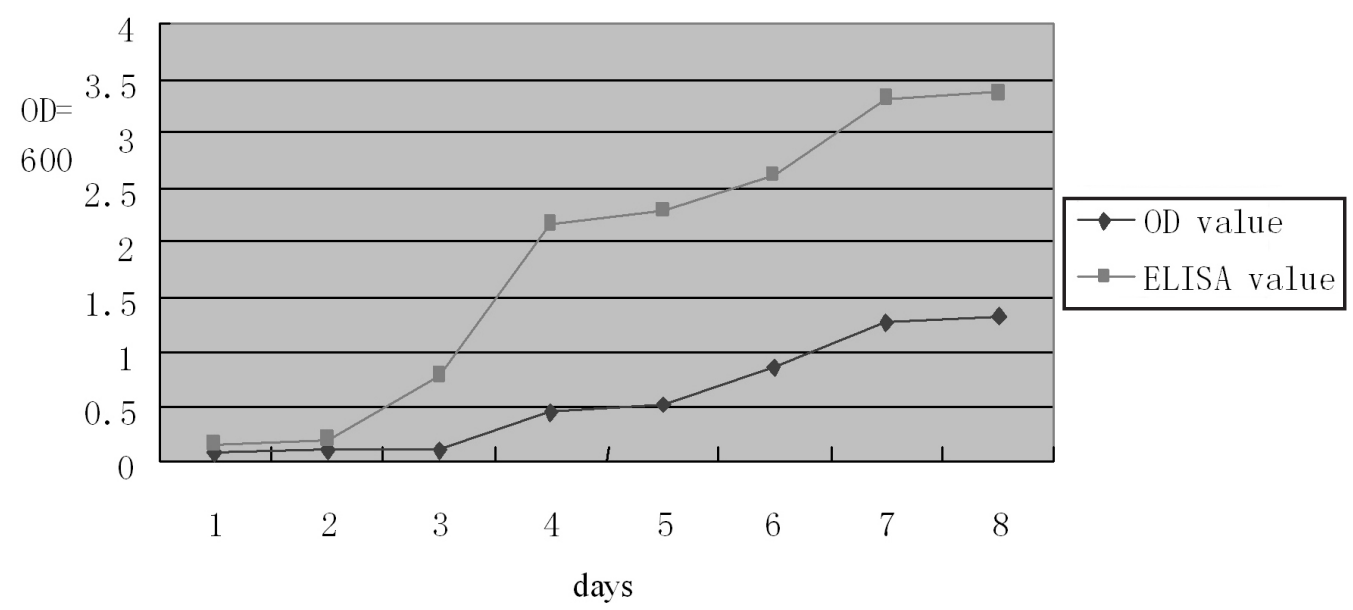

Figure 6. rBCG growth and expression of interferon curve within a week.

\section{Th1-type cytokines secreted by activated PBMCs}

The level of hIFN- $\gamma$ produced by rBCG-induced PBMCs was significantly increased compared to that in the wild-type BCG (wBCG) and MAO4-rBCG groups $(\mathrm{P}<0.05$, Figure 7). No significant difference was observed in the levels of IL-12 observed at 12 and $24 \mathrm{~h}$ in the wBCG group, MAO4-rBCG group, and rBCG group $(\mathrm{P}>0.05)$. Subsequently, a slow downward trend was observed, during which IL-12 expression in the rBCG group was significantly higher compared with that of the other 2 groups $(\mathrm{P}<0.05)$. The levels of TNF- $\alpha$ were remarkably increased at $12 \mathrm{~h}$ in each group; however, no significant difference was identified $(\mathrm{P}>0.05)$. In addition, TNF- $\alpha$ levels in the $\mathrm{rBCG}$ group were higher than those in the other 2 groups $(\mathrm{P}<0.05)$.
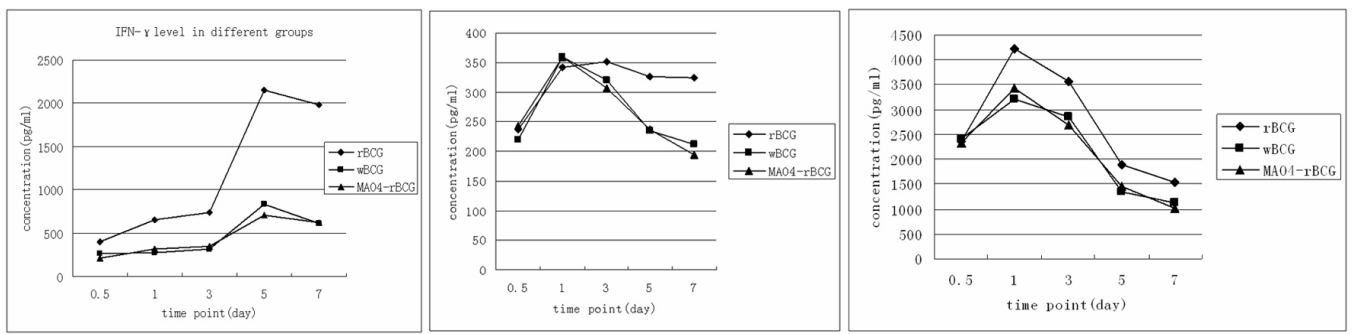

Figure 7. IFN- $\gamma, \mathrm{IL}-12$, TNF- $\alpha$ levels in different groups. 


\section{Lymphocyte proliferation induced by rBCG}

Figure 8 summarizes the proliferation of lymphocytes as determined by the MTT test, which indicated that the proliferation of lymphocytes in the $\mathrm{rBCG}$ group, BCG group, and $w B C G$ plus IFN- $\alpha-2 b$ group was higher than that in the lymphocyte group. The wBCG plus IFN- $\alpha-2 b$ group showed a higher multiplication effect than the BCG group at $48 \mathrm{~h}$, but lower than the rBCG group $(\mathrm{P}<0.05)$.

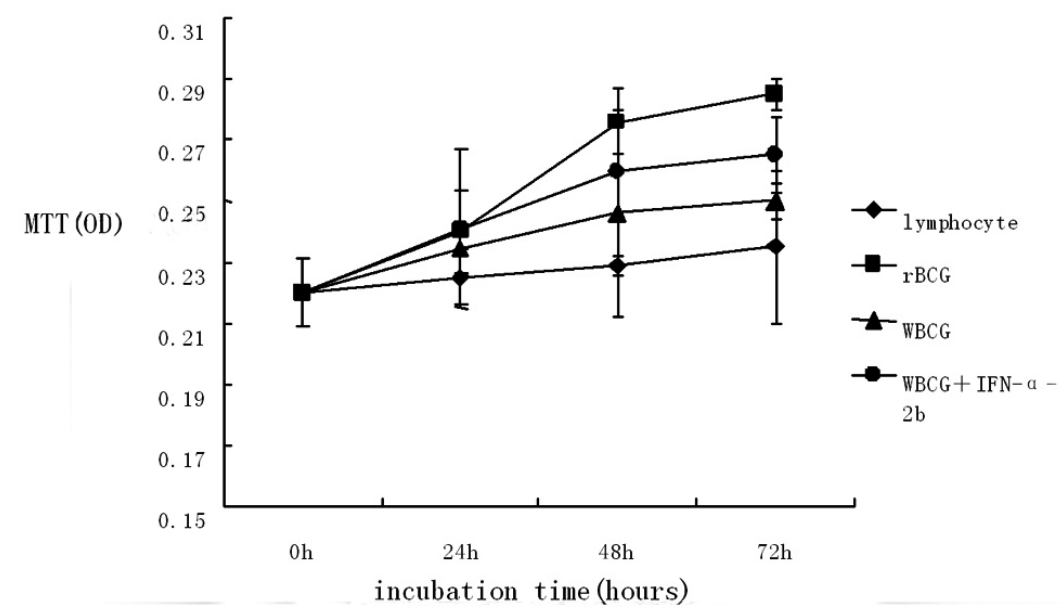

Figure 8. Comparison of the proliferation effect of lymphocyte with different group stimulation.

\section{Inhibition of bladder tumor cell growth}

Table 1 summarizes the inhibition rates of cancer cells in each group. Compared with the BCG group, remarkable inhibition was noted in the $\mathrm{BCG}$ group and the BCG plus IFN$\alpha-2 b$ group $(P<0.05)$. In each group, the cell growth inhibition rate increased with treatment time. There was no significant difference in tumor cell suppression between the BCG plus IFN- $\alpha-2 b$ group and the $r B C G$ group $(P>0.05)$.

Table1. Comparison of the EJ cell growth inhibition rate (\%).
\begin{tabular}{llcc} 
\\
Time & rBCG & wBCG & BCG+IFN- $\alpha-2 b$ \\
\hline $24 \mathrm{~h}$ & 31.38 & 21.73 & 32.40 \\
$48 \mathrm{~h}$ & 60.04 & 44.70 & 58.17 \\
$72 \mathrm{~h}$ & 79.21 & 56.21 & 69.23 \\
\hline
\end{tabular}

\section{Killing activity of rBCG-activated lymphocytes on bladder cancer cells}

The killing activity of lymphocytes activated by rBCG and BCG is detailed in Table 2. The killing activity of lymphocytes activated by rBCG was 2.67-6.74 times higher than that observed in the blank group (simple lymphocytes), 1.64-2.45 times higher that in the BCG group, and 1.25-1.66 times higher than that in the BCG plus IFN- $\alpha-2 b$ than group. The 
activity of killing EJ cells of simple lymphocytes without stimulation was $7.60 \%$; this value is much lower than that resulting from BCG stimulation after co-incubation (12.38-20.89\%) $(\mathrm{P}<0.05)$. The killing effects of activated lymphocytes stimulated with $\mathrm{rBCG}$ was highest $(20.31-51.22 \%)(P<0.05)$ among all groups, and that of the BCG plus extrinsic IFN- $\alpha-2 b$ group was $15.78-34.72 \%$, which is significantly higher than that of the $\mathrm{BCG}$ group $(\mathrm{P}<0.05)$, with a dose increase from $2.5 \mu \mathrm{L}$ to $10 \mu \mathrm{L}$. BCG-activated killer cell (BAK) killing activity also increased in each group, in which the peak was obtained with $10 \mu \mathrm{L}$, showing a significant difference between the mixed group and the $\mathrm{rBCG}$ group $(\mathrm{P}<0.05)$.

Table 2. Different concentrations of various components stimulate lymph cell damage is active (\%).

\begin{tabular}{cccc}
\hline Concentrations & rBCG & wBCG & BCG+IFN- $\alpha-2 b$ \\
\hline $2.5 \mu \mathrm{L}$ & 20.31 & 12.38 & 15.78 \\
$5.0 \mu \mathrm{L}$ & 32.73 & 16.24 & 22.92 \\
$10.0 \mu \mathrm{L}$ & 51.22 & 20.89 & 34.72 \\
$20.0 \mu \mathrm{L}$ & 30.19 & 17.46 & 24.11 \\
\hline
\end{tabular}

\section{DISCUSSION}

Intravesical BCG is widely used for treating superficial transitional cell carcinoma of the bladder (Lamm, 1992; Morales and Nickel, 1992; O'Donnell et al., 1994); however, the exact mechanism of how BCG mediates antitumor activity remains unclear. Non-muscle invasive bladder cancer shows significant recurrence and progression rates despite transurethral resection. Currently, the standard method to decrease the risk of recurrence and progression is adjuvant BCG treatment followed by BCG maintenance. Unfortunately, a significant number of patients experience recurrence and progress to invasive cancer. Thus, several randomized trials have been carried out using combination therapy to reduce recurrence and progression rates (Houghton et al., 2013). Recently, IFN $\alpha-2 b$ has been used as second-line chemotherapy for bladder cancer. Some patients with no response to BCG are sensitive to IFN. In addition, IFN shows lower local and systemic toxicity in clinical practice. Because of the short intravesical retention period of bladder perfusion, extraneous IFN fails to induce the desired immune responses. The amount of IFN used in single therapy or in combined therapy during intravesical perfusion are far beyond that required to induce local antitumor immunity, resulting in repeated perfusion and high costs.

To overcome these limitations, recombinant BCG vaccines were developed using modern genetic engineering techniques in our study to sustain secretion of hIFN- $\alpha-2 b$. BCG may bind to the bladder epithelium through fibronectin and be maintained in cells for several days or even months. Thus, recombinant interferon may be expressed in vivo. The growth curves of single hIFN- $\alpha-2 b$ and wild-type BCG plus hIFN- $\alpha-2 b$ showed no significant difference, indicating that $\mathrm{hIFN}-\alpha-2 \mathrm{~b}$ did not affect the growth of BCG.

It has been well established that human PBMCs stimulated by BCG can generate effector cells that are cytotoxic to bladder cancer cells in vitro. In this study, we found that $\mathrm{rBCG}$ showed a strong ability to activate PBMCs. In addition, the levels of IFN- $\gamma$, TNF- $\alpha$, and IL12 in the rBCG group were higher than those in the other 2 groups $(\mathrm{P}<0.05)$, demonstrating that $\mathrm{rBCG}-\mathrm{IFN} \alpha-2 \mathrm{~b}$ augmented T helper type 1 (Th1) cytokine IFN- $\gamma$ production by PBMCs. Furthermore, the level of hIFN- $\gamma$ produced by rBCG-induced PBMCs was significantly higher than that in the other 2 groups. Previous studies have demonstrated that IFN- $\gamma$, TNF- $\alpha$, and 
IL-12 are antiproliferative to cancer cells, as well as induce apoptosis (Thanhäuser et al., 1995; Brandau et al., 2000a). In addition, Luo et al. (2001) showed that the restructuring of hIFN $\alpha-2 b-r B C G$ effectively induced generation of hIFN- $\gamma$, hTNF- $\alpha$, and hIL-12, which was clearly higher than that in wild-type BCG and wild-type BCG plus IFN.

Our results showed that BCG plus IFN $\alpha-2 b$ reinforced BCG immunogenicity and promoted lymphocyte proliferation and differentiation. This is critical for BCG differentiation for IFN $\alpha-2 b$ to enhance the cytokine network control effect. As a cytokine regulating network start node, IFN $\alpha$ plays an indispensable role, and even a small amount of IFN $\alpha$ can produce network feedback.

The results of the MTT test showed lower proliferation of lymphocytes in the wildtype BCG plus IFN $\alpha-2 b$ group. After $24 \mathrm{~h}$ in the BCG plus IFN $\alpha-2 b$ group, lymphocyte proliferation was higher than that in the wild-type BCG group, and the MTT values showed that proliferation of the $\mathrm{rBCG}$ group was greater than that in the wild-type BCG group; rBCG group showed sustained release of IFN $\alpha-2 b$ under the action of IFN and BCG synergy and showed a strong stimulatory effect; lymphocyte proliferation also showed a strong growth trend. Exogenously added IFN $\alpha-2 b$ showed a reduced concentration, while wild-type BCG synergy was also reduced. Therefore, the effect of lymphocyte proliferation induced by $\mathrm{rBCG}$ was superior to that of $\mathrm{BCG}$ in vitro.

It is well known that stimulation of human PBMCs by viable BCG in vitro leads to the generation of a specialized cell population known as BAK cells (Bohle et al., 1993; Thanhäuser et al., 1993; Brandau et al., 2000b). BAK cells play an important role in the immune mechanism of the BCG anti-tumor effects and may kill bladder cancer cells through the perforin-mediated lysis pathway, which is effective for lysing natural killer cell-resistant bladder cancer cells. After BCG stimulation, lymphocytes were activated to begin proliferation, differentiation, and cytokine secretion, as well as to enhance immune activity and tumoricidal activity. $\mathrm{rBCG}$ and $\mathrm{BCG}$ plus IFN $\alpha-2 \beta$ showed a stronger ability to induce lymphocyte proliferation, differentiation, and cytokine secretion. Thus, immune activity was sharply enhanced. In our study, rBCG had more obvious antitumor effects than the mixed group. The addition of external IFN to BCG showed an increased killing effect of tumor cells. However, along with its consumption, administration of the large dose of IFN for bladder perfusion in clinical practice is not practical. According to our experimental results, the killing activity of activated rBAK increased with increasing concentration. However, a higher concentration of BCG may damage the activity by influencing lymphocyte survival and inhibit its action. $r B C G-I F N \alpha-2 b$ is an improved BCG agent that induces enhanced PBMC cytotoxicity against bladder cancer cells in vitro.

Whether rBCG can maintain the growth characteristics of BCG is unknown. Previous studies reported no significant difference in the growth and reproduction between a single copy of rBCG and BCG strains. However, multiple copies of the rBCG showed significantly lower replication. By detecting IFN during in vitro culture, we found that IFN is secreted and had complete activity. ELISA cannot be used to determine whether a protein has a complete structure and biological activity. Thus, after ELISA, biological activity was determined using a cytopathic inhibition assay. Based on the number of passages, the plasmid stability of rBCG was $>92 \%$, and no change was observed in the capacity of IFN secretion.

In our study, rBCG-IFN $\alpha-2 \mathrm{~b}$ was constructed and its biological activity was validated, revealing the immunological activities and antitumor effects on the bladder cancer cell line EJ. Our data showed that rBCG-IFN $\alpha-2 b$ significantly increased the antitumor effects of BCG 
against bladder cancer and has advantages over traditional treatment methods combining BCG and exogenous IFN- $\alpha-2 b$. Thus, this $r B C G$ strain may serve as an alternative to BCG for treating superficial bladder cancer.

\section{CONCLUSIONS}

rBCG-IFN $\alpha-2 b$ is an improved BCG agent that can induce enhanced cytotoxicity against bladder cancer cells in vitro. $\mathrm{rBCG}-\mathrm{IFN \alpha}-2 \mathrm{~b}$ may be an alternative to $\mathrm{BCG}$ for treating bladder cancer patients and reduce both the clinical dosage and side effects of BCG immunotherapy. Further studies are needed to validate the clinical applications of rBCG-IFN $\alpha-2 b$ and to reduce BCG dosage as well as to attenuate side effects and post-operation recurrence.

\section{ACKNOWLEDGMENTS}

Research supported by the Science and Technology Project of the Tianjin Municipal Health Bureau (\#11KG147).

\section{REFERENCES}

Alexandroff AB, Jackson AM, O'Donnell MA and James K (1999). BCG immunotherapy of bladder cancer: 20 years on. Lancet 353: 1689-1694.

Bohle A, Thanhäuser A, Ulmer AJ, Ernst M, et al. (1993). Dissecting the immunobiological effects of Bacillus CalmetteGuérin (BCG) in vitro: evidence of a distinct BCG-activated killer (BAK) cell phenomenon. J. Urol. 150: 1932-1937.

Brandau S, Böhle A, Thanhäuser A, Ernst M, et al. (2000a). In vitro generation of Bacillus Calmette-Guérin-activated killer cells. Clin. Infect. Dis. 31 Suppl 3: S94-S100.

Brandau S, Suttmann H, Riemensberger J, Seitzer U, et al. (2000b). Perforin-mediated lysis of tumor cells by Mycobacterium bovis Bacillus Calmette-Guérin-activated killer cells. Clin. Cancer Res. 6: 3729-3738.

Gan YH, Zhang Y, Khoo HE and Esuvaranathan K (1999). Antitumour immunity of Bacillus Calmette-Guérin and interferon alpha in murine bladder cancer. Eur. J. Cancer 35: 1123-1129.

Houghton BB, Chalasani V, Hayne D, Grimison P, et al. (2013). Intravesical chemotherapy plus bacille Calmette-Guérin in non-muscle invasive bladder cancer: a systematic review with meta-analysis. BJU Int. 111: 977-983.

Lamm DL (1992). Long-term results of intravesical therapy for superficial bladder cancer. Urol. Clin. North Am. 19: 573-580.

Luo Y, Szilvasi A, Chen X, DeWolf WC, et al. (1996). A novel method for monitoring Mycobacterium bovis BCG trafficking with recombinant BCG expressing green fluorescent protein. Clin. Diagn. Lab Immunol. 3: 761-768.

Luo Y, Chen X, Han R, and O'Donnell MA (2001). Recombinant bacille Calmette-Guérin (BCG) expressing human interferon-alpha 2B demonstrates enhanced immunogenicity. Clin. Exp. Immunol. 123: 264-270.

Morales A and Nickel JC (1992). Immunotherapy for superficial bladder cancer. A developmental and clinical overview. Urol. Clin. North Am. 19: 549-556.

Morales A, Eidinger D, Bruce AW (1976). Intracavitary bacillus Calmette-Guérin in the treatment of superficial bladder tumors [J]. J. Urol. 116: 180-183.

O'Donnell MA, Aldovini A, Duda RB, Yang H, et al. (1994). Recombinant Mycobacterium bovis BCG secreting functional interleukin-2 enhances gamma interferon production by splenocytes. Infect. Immun. 62: 2508-2514.

Sarosdy MF and Kierum CA (1989). Combination immunotherapy of murine transitional cell cancer using BCG and an interferon-inducing pyrimidinone. J. Urol. 142: 1376-1379.

Thanhäuser A, Bohle A, Flad HD, Ernst M, et al. (1993). Induction of bacillus-Calmette-Guérin-activated killer cells from human peripheral blood mononuclear cells against human bladder carcinoma cell lines in vitro. Cancer Immunol. Immunother. 37: 105-111.

Thanhäuser A, Böhle A, Schneider B, Reiling N, et al. (1995). The induction of bacillus-Calmette-Guérin-activated killer cells requires the presence of monocytes and T-helper type-1 cells. Cancer Immunol. Immunother. 40: 103-108. 